\title{
Comparison of the Characteristics and Outcomes of SARS-COV 2 Critically III Patients After Emergence of the Variant of Concern 20H/501Y.V2: A Comparative Cohort Study
}

Philippe ARIES ( $\sim$ philippe.aries@chu-brest.fr)

Department of Anesthesia and Surgical Intensive Care, Brest Teaching Hospital, Brest

Olivier HUET

Department of Anesthesia and Surgical Intensive Care, Brest Teaching Hospital, Brest

Julien BALICCHI

Regional Health Agency, Centre Kinga, Mamoudzou, Mayotte

\section{Quentin MATHAIS}

Department of Anesthesiology and Intensive Care, Military Hospital Sainte Anne, Toulon

\section{Camille ESTAGNASIE}

Intensive Care Unit, Mayotte Hospital, Mamoudzou, Mayotte

\section{Gonzague MARTIN-LECAMP}

Intensive Care Unit, Mayotte Hospital, Mamoudzou, Mayotte

\section{Anne-Cécile MORVAN}

Intensive Care Unit, Hospital of Southern Réunion, University Teaching Hospital of La Réunion, Saint-Pierre, Reunion Island

Olivier SIMON

Intensive Care Unit, Hospital of Western Réunion, Saint-Paul, Reunion Island

\section{Bérénice PUECH}

Intensive Care Unit, Félix Guyon Hospital, University Teaching Hospital of La Réunion, Saint Denis, Reunion Island

\section{Marion SUBIROS}

French Public Health Agency in the Indian Ocean Region, Mamoudzou, Mayotte

\section{Renaud BLONDE}

Intensive Care Unit, Mayotte Hospital, Mamoudzou, Mayotte

\section{Yvonnick BOUE}

Intensive Care Unit, Mayotte Hospital, Mamoudzou, Mayotte

\section{Research Article}

Keywords: COVID-19, Variant, Critically-ill patients

Posted Date: December 29th, 2021

DOI: https://doi.org/10.21203/rs.3.rs-1199981/v1

License: (c) (i) This work is licensed under a Creative Commons Attribution 4.0 International License. Read Full License 


\section{Abstract}

\section{Background}

There are currently no data regarding characteristics of critically ill patients with SARS-CoV-2 Variant of Concern (VOC) 20H/501Y.V2. We therefore aimed to describe changes of characteristics in critically ill patients with Covid-19 between the first and the second wave when viral genome sequencing indicated that VOC was largely dominant in Mayotte Island (Indian Ocean).

\section{Methods}

Consecutive patients with Covid-19 and over 18 years admitted in the unique Intensive Care Unit (ICU) of Mayotte during wave 2 were compared with an historical cohort of patients admitted during wave 1. We performed a Logistic Regression (LR) comparing wave 1 and wave 2 as outcomes. To complete analysis of changes in characteristics and outcomes, we built a Random Forest model (RF) -i.e., a machine learning classification tool- using the same variable set as that of the LR.

\section{Results}

We included 156 patients, 41 (26.3\%) and 115 (73.7\%) belonging to the first and second waves respectively. Univariate analysis did not find difference in demographic data or in mortality. Our multivariate LR found that patients in wave 2 had less fever (absence of fever aOR 5.23, 95\% Cl $1.89-14.48, p=0.001$ ) and a lower SAPS II (aOR 0.95, 95\% Cl $0.91-0.99, p=0.007)$ at admission; at 24 hours, the need of invasive mechanical ventilation was higher ( $\mathrm{aOR} 3.49,95 \% \mathrm{Cl} 0.98-12.51, p=0.055)$ and p02/FiO2 ratio was lower (aOR 0.99, $95 \% \mathrm{Cl} 0.98-0.99, p=0.03$ ). Patients in wave 2 had also an increased risk of VAP (aOR 4.64, $95 \% \mathrm{Cl} 1.54-13.93, p=0.006)$. Occurrence of VAP was also a key variable to classify patients between wave 1 and wave 2 in the variable importance plot of the RF model.

\section{Conclusion}

Our data suggested that $\mathrm{VOC} 20 \mathrm{H} / 501 \mathrm{Y} . \mathrm{V} 2$ could be associated with a higher severity of respiratory failure at admission and a higher risk for developing VAP. We hypothesized that the expected gain in survival brought by recent improvements in critical care management could have been mitigated by increased transmissibility of the new lineage leading to admission of more severe patients. The immunological role of VOC $20 \mathrm{H} / 501 \mathrm{Y} . \mathrm{V} 2$ in the propensity for VAP requires further investigations.

\section{Background}

The coronavirus disease 2019 (Covid-19) pandemic continues in the world, with recent estimates of more than 268 million cases diagnosed and more than 5 million deaths [1]. Multiple variants of the Severe Acute Respiratory Syndrome Coronavirus 2 (SARSCoV-2), the causative agent of Covid-19, have been observed worldwide. A variant has one or more mutations that differentiate it from the ancestral Ribonucleic Acid (RNA) virus and from other variants. Among them, variant 20H/501Y.V2 (also known as variant Beta or B.1.351) has been characterized as a Variant Of Concern (VOC) i.e. a variant for which there is evidence of an increase in transmissibility, an increase in symptom severity (e.g., increased hospitalizations or deaths), significant reduction in neutralization by antibodies generated during previous infection or vaccination, reduced effectiveness of treatments or vaccines, or diagnostic detection failures [2].

Variant 20H/501Y.V2 is associated with multiple mutations in spike protein [3] and emerged in September 2020 in South Africa [4] before spreading worldwide. Variant 20H/501Y.V2 was the most common strain in some French regions between April and May 2021[5].

There are currently limited data regarding clinical differences between Covid-19 disease caused by different variants especially for VOC 20H/501Y.V2. This VOC has been associated with an increased severity of the disease and increased in-hospital mortality [6,7] especially in patients older than 60 years [8]. However, clinical characteristics of critically ill patients remain undescribed. 
Mayotte Island is an overseas department of France located in the Indian Ocean. The first case of Covid-19 was diagnosed in week 11, 2020 and the epidemic peak of the first wave was reached in May 2020. A few weeks after the emergence of the VOC 20H/501Y.V2 in South Africa, Mayotte Island experienced a new and more dramatic second wave, which peaked in week 5, 2021. During week 5 and week 6 , all SARS-Cov-2 positive samples were analyzed and more than $80 \%$ of them (150/172) pointed to 20H/501Y.V2 variant. Moreover, in the same period viral whole genome sequencing was performed for 23 critically ill patients: $87 \%(\mathrm{~N}=20)$ were infected by the $20 \mathrm{H} / 501 \mathrm{Y} . \mathrm{V} 2$ variant $[9,10]$. Therefore VOC $20 \mathrm{H} / 501 \mathrm{Y} . \mathrm{V} 2$ was considered as dominant during the second wave in Mayotte Island. The Intensive Care Unit (ICU) of the Mayotte's Hospital, a 16 beds unit, is the unique structure for critically ill patients on the island. This specificity allowed us to make a rigorous comparison between both waves and avoided interhospital variability previously reported in epidemiological studies for Covid-19 patients [11]

We therefore aimed to describe changes in the characteristics of critically ill patients with Covid-19 after the emergence of the VOC 20H/501Y.V2 by comparing the clinical profile of patients hospitalized during the first and second waves of the SARS-Cov 2 pandemic.

\section{Methods}

\section{Study design, waves and subjects definitions}

We performed a comparative cohort study in the Mayotte Hospital. All consecutive patients over 18 years of age admitted in ICU with laboratory-confirmed Severe Acute Respiratory Syndrome Coronavirus 2 (SARS-CoV 2) infection were retrospectively included in wave 1 and prospectively included in wave 2. The waves periods were defined using ICU admission data. The first wave was the period from the start of the pandemic i.e., March 15, 2020 (W12-2020) to September 27, 2020 (W39-2020); and the second wave was defined from February 01, 2021 (W5-2021 to March 01, 2021 (W9-2021). Wave 2 was considered starting when viral whole genome sequencing results indicated that VOC 20H/501Y.V2 was predominant in Mayotte Island $[9,10]$ as it has been in South Africa [3]. Patients admitted to ICU between these two periods were excluded to avoid risk of overlap between infection by Beta variant and the wild type virus. Laboratory confirmation for SARS-CoV-2 was defined as a positive result of real-time reverse transcriptase-polymerase chain reaction (RTPCR) assay from either nasal or pharyngeal swabs, or lower respiratory tract samples.

Our study received approval from the ethical committee of the French Society of Anesthesia and Intensive Care Medicine (IRB 00010254 - 2021 - 080) in accordance with our local regulations. All patients or close relatives were informed that their data were included in the study when possible.

Reporting of the study followed the STROBE guidelines.[12]

\section{Data collection and outcomes}

We collected in health care records demographic data, medical history, comorbidities, the clinical frailty scale (a patient with a score $\geq 5$ was considered frail [13]) and symptoms before admission. We also collected signs at admission, ROX index for patients under oxygen therapy [14], laboratory results and computed Tomographic (CT) scans (visual quantification was used to classify patients as per the percentage of lung parenchyma affected $[15,16])$ at admission.

Disease severity at ICU admission was evaluated using SOFA score, WHO Clinical Progression Scale [17], and SAPS II score. SOFA score and WHO Clinical Progression Scale were also evaluated at 24 hours of ICU admission.

Clinical evolution at 24-hours, use of adjunct measures (i.e., corticosteroids, neuromuscular blockers, nitric oxide, invasive therapies, prone positioning) and in-hospital complications (i.e., myocarditis, bradycardia under $50 \mathrm{bpm}$, neurocovid defined as SARS-Cov-2 positive samples in cerebrospinal fluid, thrombosis, coinfections and bacterial cultures results) were also recorded. A 
diagnosis of Ventilator-Associated Pneumonia (VAP) was made in case of clinical and radiological signs associated to bacterial documentation.

Finally, we evaluated the following outcomes: duration of mechanical ventilation, Ventilator-free days at 28 days (VFD28) [17] (defined as the number of days with successful cessation (alive and free) from invasive mechanical ventilation for at least $48 \mathrm{~h}$ without reintubation in patients who survived 28 days after ICU admission, whereas for patients ventilated 28 days or more, or who died within 28 days ventilator-free days were zero), the need for medical evacuation, the dates of ICU and hospital discharge, and vital status at 28 days after ICU admission.

In case of Aero-medical evacuation for patient, the three receiving hospitals (University Teaching Hospital of Saint Pierre, La Réunion, University Teaching Hospital of Saint Denis, La Réunion and Hospital of Western Réunion) collected data using the same definitions.

\section{Statistical analysis}

No statistical sample size calculation was made and sample size was equal to the number of patients admitted to the ICU during both defined periods. Characteristics of patients were described as frequencies and percentages for categorical variables, as means and standard deviations (SD) or medians and interquartile ranges (IQR) for continuous variables. Categorical variables were compared by Chi-square or Fisher's exact test. After testing for normality (kolmogorov-Smirnov test) and for equality of variances (Fisher-Snedecor test), continuous variables were compared either by Student's t test, Welch's t-test or Wilcoxon's ranksum test. Tests were two-sided and values of $p$ less than 0.05 were considered statistically significant. Missing data was not imputed.

In order to compare the characteristics of Covid-19 patients admitted to ICU during wave 1 and wave 2, we performed a Logistic Regression (LR). Variables significantly associated in bivariate analysis with a value of $p<0.10$ and with less than $10 \%$ missing data were included in the LR model. Results were presented as adjusted odds ratios (aOR) with their $95 \%$ confidence intervals (OR, $95 \% \mathrm{Cl})$.

To complete analysis of changes in characteristics and outcomes, we built a Random Forest model (RF) -i.e., a machine learning classification tool- using the same variable set as that of the LR.

Random Forest built a multitude of decision trees based on bootstrap sampling of the training dataset. The variables in each tree were randomly selected. Algorithm aggregated the results of multiple decision trees via majority voting.[19] We set the number of multiple decision trees as 5000 and the number of variables used in a decision tree was 2 . The RF model can provide importance ranking of the predictor variables using the Mean Decrease Accuracy (MDA) plot and the Mean Decrease in Gini (MDG) coefficient. The MDA plot expresses for all variable how much accuracy the model losses by excluding the variable. The more the accuracy suffers, the more important the variable is for classification. The MDG coefficient is a measure of how a variable contributes to the homogeneity of the nodes and leaves in the Random Forest model. The higher the value of MDA of MDG for a variable, the higher the importance of the variable in the model.

The prediction performance of the models was assessed by the area under the receiver operating characteristic curve (AUROC).

The statistical analysis was implemented using SAS (Enterprise Guide 7.11) and R (1.1.463).

\section{Results}

We included 156 patients among 190 assessed for eligibility, 41 during the first wave and 115 during the second wave. Thirty-four patients were excluded for risk of overlap between variant and wild-type virus. Six patients enrolled were lost to follow-up at Day-

\section{8. (Figure 1)}

During the first wave, the peak of weekly new admissions in ICU was reached in W21-2020 with 8 new patients admitted in a week. During the second wave in 2021, hospital was rapidly overloaded and the peak in ICU was reached in W7-2021 with 36 new 


\section{Univariate analysis of characteristics and outcomes}

We did not observe significant differences in basic demographic data and comorbidities between both waves. (Table 1) However, during the second waves, patients had less fever before admission and at ICU admission (47 vs $73.2 \%$ before admission, $p=0.007$ and 31.9 vs $58.5 \%$ at admission, $p=0.005)$. The rate of patients with invasive mechanical ventilation and p02/FiO2 ratio $<150 \mathrm{mmHg}$ at admission (WHO Clinical Progression Scale) was higher during wave 2 (14.6 vs $21.7 \% p=0.03$ ). We did not find difference concerning laboratory results and comparison of percentage of lung parenchyma affected was not possible because of the proportion of missing data during the first wave (44.7\%).

Analysis of adjunct measures showed differences between both waves with much more days of continuous neuromuscular blockade (7.51 vs 6.89 days, $p=0.029)$, more use of corticosteroids (100 vs $20 \%, p<0.001)$, and nitric oxide use (20 vs $2.4 \%$, $p=0.015$ ) during wave 2 . The second wave was also associated with an increased rate of Ventilator Associated Pneumonia (VAP) (57.4 vs $26.8 \%, p=0.001)$.

We did not find significant difference for outcomes except for the rate of Aero-medical evacuation that was significantly higher during wave 2 (58.3 vs7.7\%, $p<0.001)$. (Table 2)

\section{Table 1}

Demographic, clinical, and ventilatory support characteristics at admission of patients according to the wave. 


\begin{tabular}{|c|c|c|c|}
\hline & $\begin{array}{l}\text { First wave } \\
(n=41)\end{array}$ & $\begin{array}{l}\text { Second wave } \\
(n=115)\end{array}$ & $P$ value \\
\hline \multicolumn{4}{|l|}{ Patient's characteristics } \\
\hline \multicolumn{4}{|l|}{ Sex-no.(\%) } \\
\hline Male & $26(63.4)$ & $73(63.5)$ & 1.00 \\
\hline Female & $15(36.6)$ & $42(36.5)$ & \\
\hline Age, years & $60(51-67)$ & $57(46-66)$ & 0.66 \\
\hline Body mass index, $\mathrm{Kg} / \mathrm{m}^{2}$ & 28.(24-33.09) & $29.40(26.53-34.70)$ & 0.22 \\
\hline Known diabetes & $22(53.7)$ & $59(51.3)$ & 0.94 \\
\hline Traited hypertension & $25(61.0)$ & $63(54.8)$ & 0.62 \\
\hline Immunodeficiency ${ }^{a}$ & $2(4.9)$ & $6(5.2)$ & 1.00 \\
\hline Chronic kidney disease & $8(19.5)$ & $11(9.6)$ & 0.16 \\
\hline Dialysis & $1(2.4)$ & $1(0.9)$ & 1.00 \\
\hline Chronic respiratory disease & $1(2.4)$ & $7(6.1)$ & 0.61 \\
\hline Active smokers & $1(2.4)$ & $5(4.3)$ & 0.94 \\
\hline Pregnancy & $1(2.4)$ & $6(5.2)$ & 0.77 \\
\hline Clinical_Frailty_Scale $>5$ & $0(0)$ & $7(0.06)$ & 0.43 \\
\hline \multicolumn{4}{|l|}{ Symptoms before ICU admission } \\
\hline Cough & $22(53.7)$ & $74(64.3)$ & 0.31 \\
\hline Shortness of breath & $37(90.2)$ & $112(97.4)$ & 0.15 \\
\hline Chest pain & $3(7.3)$ & $7(6.1)$ & 1.00 \\
\hline Anosmia, ageusia & $3(7.3)$ & $11(9.6)$ & 0.90 \\
\hline Myalgia & $6(14.6)$ & $12(10.4)$ & 0.66 \\
\hline Fever & $30(73.2)$ & $54(47.0)$ & 0.007 \\
\hline Headaches & $9(22.0)$ & $23(20.0)$ & 0.97 \\
\hline Diarrhea & $2(4.9)$ & $7(6.1)$ & 1.00 \\
\hline Altered mental function & $3(7.3)$ & $11(9.6)$ & 0.91 \\
\hline Vomitings & $2(5.0)$ & $6(5.2)$ & 1.00 \\
\hline \multicolumn{4}{|l|}{ Clinical characteristics and ICU Scores at admission } \\
\hline Delay between first symptoms and ICU admission & $6(3-8)$ & $7(4-9)$ & 0.25 \\
\hline Fever & $24(58.5)$ & $36(31.9)$ & 0.005 \\
\hline IGS2 score & $39(32-49)$ & $35(29-41)$ & 0.08 \\
\hline SOFA score & $3(2-5)$ & $3(2-4)$ & 0.62 \\
\hline WHO Clinical Progression Scale & & & 0.03 \\
\hline Oxygen by mask or nasal prongs & $4(9.8)$ & $1(0.9)$ & \\
\hline Oxygen by NIV or High flow & $29(70.7)$ & $79(68.7)$ & \\
\hline
\end{tabular}




\begin{tabular}{|c|c|c|c|}
\hline & $\begin{array}{l}\text { First wave } \\
(n=41)\end{array}$ & $\begin{array}{l}\text { Second wave } \\
(n=115)\end{array}$ & $P$ value \\
\hline \multicolumn{4}{|l|}{ Clinical characteristics and Score at 24 hours } \\
\hline SOFA score & $4(2-6)$ & $4(2-6)$ & 0.90 \\
\hline ROX index (for patients under oxygen therapy) & $6.85(4.79-8.8)$ & $6.05(5.05-9.57)$ & 0.64 \\
\hline Invasive Mechanical Ventilation & $27(65.9)$ & $97(84.3)$ & 0.01 \\
\hline WHO Clinical Progression Scale & & & 0.57 \\
\hline Oxygen by mask or nasal prongs & $1(2.4)$ & $3(2.6)$ & \\
\hline Oxygen by NIV or High flow & $18(43.9)$ & $33(28.7)$ & \\
\hline $\begin{array}{l}\text { Mechanical ventilation, } \\
\text { p02/FiO2 } \mathrm{mmHg}>150\end{array}$ & $11(26.8)$ & $35(30.4)$ & \\
\hline $\begin{array}{l}\text { Mechanical ventilation, } \\
\text { p02/FiO2 } \mathrm{mmHg}<150\end{array}$ & $10(24.4)$ & $39(33.9)$ & \\
\hline Extracorporeal membrane oxygenation (ECMO) & $1(2.4)$ & $3(2.6)$ & \\
\hline Death & $0(0.0)$ & $2(1.7)$ & \\
\hline \multicolumn{4}{|l|}{ Blood gases at 24 hours } \\
\hline $\mathrm{pH}$ & $7.43(7.36-7.47)$ & $7.42(7.37-7.47)$ & 0.70 \\
\hline $\mathrm{PaCO} 2, \mathrm{mmHg}$ & $38(32-43)$ & $40.5(35-45)$ & 0.15 \\
\hline $\mathrm{HCO} 3, \mathrm{mmol} / \mathrm{L}$ & $26(22-28)$ & $27.10(24-29.9)$ & 0.02 \\
\hline Lactate, $\mathrm{mmol} / \mathrm{L}$ & $1.2(0.9-1.5)$ & $1.4(1.1-1.7)$ & 0.02 \\
\hline $\mathrm{PaO} 2 / \mathrm{FiO} 2$ & $150(121-215)$ & $136(105-175)$ & 0.06 \\
\hline \multicolumn{4}{|l|}{ Adjunct measures } \\
\hline Corticosteroids ${ }^{a}$ & $8(20.0)$ & $112(100.0)$ & $<0.001$ \\
\hline Continuous neuromuscular blockade, days & $3(1-6)$ & $6(1-12)$ & 0.01 \\
\hline Prone positioning, days & $1(0-2)$ & $2(0-4)$ & 0.12 \\
\hline ECMO & $2(0.05)$ & $4(0.03)$ & 0.40 \\
\hline Tracheotomy & $7(17.1)$ & $13(11.3)$ & 0.50 \\
\hline Nitric oxide & $1(2.4)$ & $23(20.0)$ & 0.02 \\
\hline \multicolumn{4}{|l|}{ Major complications during ICU stay } \\
\hline Myocarditis & $1(2.7)$ & $8(7.0)$ & 0.58 \\
\hline Days between myocarditis onset and first symptoms & $14.00(8.5-19.5)$ & 9.5 (7.5-14) & 0.20 \\
\hline Bradycardia ${ }^{b}$ & $1(2.7)$ & $17(14.8)$ & 0.09 \\
\hline Neurocovid ${ }^{c}$ & $0(0.0)$ & $1(3.4)$ & 1.00 \\
\hline Thrombosis $^{d}$ & & & 0.06 \\
\hline
\end{tabular}




\begin{tabular}{|c|c|c|c|}
\hline Venous & $0(0.0)$ & $9(8.2)$ & \\
\hline Pulmonary embolism & $0(0.0)$ & $3(2.7)$ & \\
\hline Artery & $1(4.5)$ & $0(0.0)$ & \\
\hline Ventilator Associated Pneumonia & $11(26.8)$ & $66(57.4)$ & 0.001 \\
\hline \multicolumn{4}{|l|}{ Outcomes } \\
\hline Duration of invasive ventilation, days & $13(7-24)$ & $17(10-28)$ & 0.28 \\
\hline VFD28 & $0.5(0-8)$ & $0(0-13)$ & 0.97 \\
\hline ICU length of stay, days & $9(6-27)$ & $16(9.5-28)$ & 0.09 \\
\hline Hospital length of stay, days & $20(10-31)$ & $19(12-31)$ & 0.65 \\
\hline Day 28 mortality & $10(25.6)$ & $36(31.3)$ & 0.64 \\
\hline Areo-Medical evacuation & $3(7.7)$ & $67(58.3)$ & $<0.001$ \\
\hline \multicolumn{4}{|c|}{$\begin{array}{l}\text { SOFA: Sequential Organ Failure Assessment; ECMO: Extracorporeal Membrane Oxygenation; ICU: Intensive } \\
\text { Care Unit; NIV: Non-Invasive Ventilation; VFD28: Ventilator-free days at } 28 \text { days. } \\
\text { a According to RECOVERY protocol[38], }{ }^{\mathrm{b}} \text { Bradycardia under } 50 \mathrm{bpm}{ }^{\mathrm{c}} \text { SARS-Cov-2 positive samples in } \\
\text { cerebrospinal fluid, }{ }^{\mathrm{d}} \text { Proven venous or arterial thrombosis }\end{array}$} \\
\hline
\end{tabular}

\section{Multivariate analysis of characteristics and outcomes according to the wave}

Our Logistic Regression (LR) analysis found that patients in wave 2 had less fever (aOR absence of fever: $5.23,95 \% \mathrm{Cl} 1.89$ $14.48, p=0.0014$ ), a lower SAPS II at admission (aOR $0.95,95 \% \mathrm{Cl} 0.91-0.99, p=0.0075$ ). Concerning outcomes, we found that wave 2 was associated with a higher rate of invasive mechanical ventilation at 24 hours (aOR $3.49,95 \% \mathrm{Cl} 0.98-12.51$, $p=0.055$ ), a lower p02/FiO2 ratio at 24 hours ( $\mathrm{aOR} 0.99,95 \% \mathrm{Cl} 0.98-0.99, p=0.0309$ ) and an increased risk of VAP (aOR 4.64, $95 \% \mathrm{Cl} 1.54-13.93, p=0.0063$ ). (Table 3) The AUROC for LR model was 0.797 , and accuracy was $82 \%$. (Table 4)

Table 3

Multivariate Analysis of Factors Associated with Wave 2

\section{Contribution of machine learning model in determination of waves characteristics}

Variable importance plot based on Random Forest model showed that absence of fever at admission and VAP were the most important variables to classify patients between wave 1 and wave 2. (Figure 3) The AUROC for RF model was 0.678. (Table 4)

Table 4

Models, prediction performance and parameters. 


\begin{tabular}{|llc|}
\hline Clinical Features & OR [95\% CI] & $p$-value \\
\hline Absence of fever at admission & $5.23[1.89 ; 14.48]$ & 0.0014 \\
\hline SAPS II at admission & $0.95[0.91 ; 0.99]$ & 0.0075 \\
\hline Invasive mechanical ventilation at 24 hours & $3.49[0.98 ; 12.52]$ & 0.0550 \\
\hline pO2/FiO2 ratio at 24 hours & $0.99[0.98 ; 0.99]$ & 0.0309 \\
\hline VAP & & 0.0063 \\
\hline Cl: Confidence Interval; VAP: Ventilator Acquired Pneumonia; SAPS: Simplified Acute Physiology score; \\
\hline
\end{tabular}

\begin{tabular}{|c|c|c|c|c|c|c|c|c|c|}
\hline Model & Variables & AUROC & Specificity & Sensibility & NPV & PPV & $\begin{array}{l}\text { Model } \\
\text { Accuracy }\end{array}$ & $\mathbf{N}$ & Parameters \\
\hline $\begin{array}{l}\text { Logistic } \\
\text { Regression }\end{array}$ & $\begin{array}{l}\text { Fever at } \\
\text { admission+SAPS* } \\
\text { II+IMV*+paO2/FiO2 } \\
\text { ratio*+VAP }\end{array}$ & 0.797 & $36 \%$ & $96 \%$ & $75 \%$ & $83 \%$ & $82 \%$ & $\begin{array}{l}n=131 \\
\text { (wave } \\
1=32 ; \\
\text { Wave } \\
2=99 \text { ) }\end{array}$ & \\
\hline $\begin{array}{l}\text { Random } \\
\text { Forest }\end{array}$ & $\begin{array}{l}\text { Fever at } \\
\text { admission+SAPS* } \\
\text { II+IMV*+paO2/FiO2 } \\
\text { ratio*+VAP }\end{array}$ & 0.678 & $28 \%$ & $95 \%$ & $64 \%$ & $80 \%$ & $77 \%$ & $\begin{array}{l}n=131 \\
\text { (wave } \\
1=32 ; \\
\text { Wave } \\
2=99 \text { ) }\end{array}$ & $\begin{array}{l}\text { n-nodes:15 } \\
\text { n- } \\
\text { trees:5000 } \\
\text { n- } \\
\text { variables:2 } \\
\text { OOB:2/3 vs } \\
\text { 1/3 }\end{array}$ \\
\hline $\begin{array}{l}\text { *at } 24 \text { hou } \\
\text { PLS: Parti } \\
\text { Curve; OO }\end{array}$ & $\begin{array}{l}\text { S } \\
1 \text { Least Squares; IM } \\
\text { : Out of Bag. }\end{array}$ & I: Invasi & Mechanic & Ventilatio & AUH & C: Ar & a Under & ceiver & perating \\
\hline
\end{tabular}

\section{Discussion}

To our knowledge, this is the first study to report changes in the characteristics of critically ill patients with acute respiratory failure due to Covid-19 after the emergence of the VOC 20H/501Y.V2. Demographic characteristics were similar between both waves, and our multivariate analysis associated with a machine learning method found that patients of wave 2 had less fever and had a lower illness severity score (SAPS II) at admission, but they were also more hypoxemic and more mechanically ventilated at 24 hours after admission and finally developed more VAP during their ICU stay.

Experience gained during the first wave and specific therapies have been associated to a better outcome among critically ill Covid19 patients admitted during second waves across the world.[20-22] Among these therapies, the introduction of corticosteroids 
have been associated to a lower proportion of patients requiring invasive mechanical ventilation and to reduced mortality [25]. Interestingly, despite implementation of a protocol for corticosteroids in our ICU, we did not found difference of mortality between both waves.

It has been suggested that VOC 20H/501Y.V2 could be associated to a higher hospital morbidity and mortality rate [26,27], therefore in our study the expected gain in survival brought by improvements in critical care management could have been mitigated by increased severity of the new lineage. However, changes in morbidity and mortality rates of patients with SARS-CoV2 infection should be interpreted with caution. Independently of virus virulence, Covid-19 outcomes can largely be affected by the epidemiological context i.e. population structure, climate, and social practice for example. [28] The observational nature of previous studies implies possible unmeasured confounders factors. Moreover, hospital mortality and ICU mortality can differ largely because of very different fatality rates. In our study, higher rate of VAP, increased duration of invasive mechanical ventilation and of ICU length of stay could have directly contributed to mitigate outcome improvement.

We observed that despite similar SOFA score and slightly decreased SAPS II at admission, patients in wave 2 needed more invasive mechanical ventilation ( $\mathrm{aOR} 3.49,95 \% \mathrm{Cl} 0.98-12.51, p=0.055)$ and had a lower p02/FiO2 ratio at 24 hours (aOR 0.99 , $95 \% \mathrm{Cl} 0.98-0.99, p=0.0309$ ). These results are in line with a recent study of Carbonell et al, comparing mortality in ICU between waves in a multicenter retrospective cohort. Authors found a significant lower illness severity at admission but also a trend for an increased severity of respiratory failure at admission (lower p02/FiO2 ratio) during wave 2 and 3 in Europe when higher incidence of cases led to ICU overload.[29]

During wave 2, when VOC 20H/501Y.V2 was the dominant lineage, Mayotte Island experienced a rapid and intense deterioration of the epidemiological situation. At the epidemic peak, reached in the first weeks of February, Incidence Rate (IR) was 851/100,000, (i.e., 2,378 new confirmed cases in the week) and Positive Rate (PR) was 28\%.[9] The unique hospital of Mayotte was rapidly overloaded with a peak of new admissions reached in W6-2021 (225 patients hospitalized including 30 to ICU). For comparison during the peak of wave 1, 54 patients were hospitalized including 8 in ICU in a week [10]. This epidemiological situation could be explained by an increased transmissibility of VOC 20H/501Y.V2 compared to wild lineage[4].

We observed that delay between first signs and hospital admission was increased during wave 2, 7 days (4-9) vs 6 days (3-8). As previously suggested, in an overwhelmed health system, individuals might avoid seeking care until later stage of disease [27]. Likewise, recent studies have reported association between hospital and ICU load and increased mortality.[30,31] Therefore, we hypothesize that increased transmissibility of VOC 20H/501Y.V2 during wave 2 led to hospital and ICU capacity overload and thus to admission of patients with more severe respiratory failure.

An important finding of the study was that, using the same definition of VAP between both cohorts, we found a much higher incidence of VAP during the second wave compared to the first wave $(57.4 \%$ vs $26.8 \%, \mathrm{p}=0.001)$. VAP was independently associated with wave 2 (aOR 4.64, $95 \mathrm{Cl} 1.54-13.93, p=0.0063$ ) after adjusting for invasive ventilation and p02/FiO2 ratio at 24 hours. In a recent multicentric cohort comparing mortality between three waves in critically ill patients, Carbonell et al, also found an increased rate of VAP during second and third waves in Europe.[29]. The large use of immunosuppressive agents (corticosteroids) during wave 2 could explain this finding. However, Ritter et al, showed in an observational study, after adjusting for competing risks, that corticosteroids seemed to have no impact on the likelihood of developing VAP [32].

The higher rate of VAP during wave 2 could also be explained by an increased rate of invasive mechanical ventilation during the first 24 hours and with an increased duration of mechanical ventilation.

Finally, it is possible that VOC $20 \mathrm{H} / 501 \mathrm{Y} . \mathrm{V} 2$ itself played a role immunologically in the propensity for VAP. Indeed, it has been reported that critically-ill patients with Covid-19 patients suffered from a considerable burden of immunoparesis, due to impaired immune cell function [33,34]. Since the beginning of the surge, the incidence of VAP is found higher in patients with SARS-CoV-2 infection, as compared to patients with influenza pneumonia, or no viral infection.[35,36] However, to date, specific effect on immune response of variants in critically-ill patients remains non-investigated.

The rate of comorbidities in our population was in line with previous studies except for diabetes, more frequent than previously reported $[21,37]$. Mayotte is the poorest and most densely populated territory in France with poor socio-economic and health 
conditions and prevalence of comorbidities such as diabetes is high [38]. Interestingly, although second waves across the world have been frequently associated to younger patients with fewer comorbidities [20] we did not observe difference in demographic data between both waves. It has been proposed that the most vulnerable patients as older people and those with comorbidities were likely to die during first waves [39]. However, wave 1 in Mayotte was much less intense than in other regions of the world. Therefore, specificities of the epidemic in Mayotte could explain the absence of change in profile of Covid-19 critically-ill patients between both waves.

Our study has some important strengths. First, to our knowledge, we describe for the first-time clinical characteristics and outcomes of critically ill patients with VOC 20H/501Y.V2. Second, we performed a detailed report of physiological, clinical features, and ventilatory management using the recent recommended WHO Clinical Progression Scale that has been developed to facilitate data pooling across cohort studies and clinical trials. [17] Third, we found similar typology of the patients at admission during both waves making relevant the comparison of outcomes. Fourth, the proportion of missing data was very low. Fifth, we performed the comparison between both waves in the only ICU of the island avoiding hospital variability previously described for Covid-19 patients [11]. Lastly, addition of a machine learning method to the logistic regression allowed to improve characterization of variables associated to wave 2. Contrary to other machine learning classification tools, the logic of RF algorithm is understandable for clinicians, moreover RF model can provide importance ranking of the variables.

We acknowledge several limitations to our study. First, we performed a retrospective analysis with risk of mis-classification bias. Second, our study took place Mayotte Island, potentially limiting generalizability to other hospitals. Indeed, this population is known to have higher prevalence of cardiometabolic comorbidities and socioeconomic vulnerabilities. Studies among more ethnically and geographically diverse cohorts are needed to confirm our hypothesis concerning VOC 20H/501Y.V2. Third, we performed a description of changes in the characteristics of critically ill patients with Covid-19 in the first and second wave as a proxy for dominant lineage and we have individual-level data on lineage only for 23 critically-ill patients. However, during two days in the first half of February, all usable SARS-Cov-2 positive samples were screened and more than $80 \%$ of them (150/172) pointed to $20 \mathrm{H} / 501$ Y.V2 variant. Lastly, we could not assess statistically the association of the ICU overload and outcomes.

\section{Conclusion}

Our data described emergence of SARS-Cov-2 VOC 20H/501Y.V2 in critically ill patients. It was associated with an increased severity of respiratory failure on admission and more risk for VAP without an increase of mortality. We hypothesized that the expected gain in survival brought by recent improvements in critical care management could have been mitigated by increased transmissibility of the new lineage leading to more severe patients on admission in ICU. The immunological role of VOC 20H/501Y.V2 in the propensity for VAP requires further investigations. Studies with geographically diverse cohorts and complete individual lineage data are needed to confirm our findings about this variant.

\section{Declarations}

\section{Ethical Approval and Consent to participate}

The study was approved by the ethical committee of the French Society of Anesthesia and Intensive Care Medicine. (IRB $00010254-2021-080)$

All patients or close relatives were informed that their data were included in the study when possible.

\section{Consent for publication}

Not applicable.

\section{Availability of supporting data}


The datasets used and/or analyzed during the current study are available from the corresponding author on reasonable request.

\section{Competitive interests}

The authors have disclosed that they do not have conflict of interest.

\section{Funding}

This work has not received any funding.

\section{Authors' contributions}

$\mathrm{PA}, \mathrm{YB}, \mathrm{RB}$ and $\mathrm{OH}$ designed the study. QM, CE, GML, ACM, OS and BP acquired the data. PA and JB did the statistical analysis. $\mathrm{PA}, \mathrm{YB}$ and $\mathrm{OH}$ analyzed and interpreted the data. $\mathrm{PA}, \mathrm{YB}$ and $\mathrm{OH}$ drafted the manuscript. All authors critically reviewed the manuscript and approved the final report.

\section{Acknowledgements}

The authors thank Patrice COMBE, M.D. (Medical Biology Laboratory, Mayotte Hospital, Mamoudzou, Mayotte, France) for data concerning RTPCR. Moreover, the authors pay a great tribute to the Réunion and Mayotte hospital's ICU teams involved during the health crisis.

\section{References}

1. COVID-19 Map - Johns Hopkins Coronavirus Resource Center. . Accessed 1 Nov 2021.

2. SARS-CoV-2 Variant Classifications and Definitions. . Accessed 27 Nov 2021.

3. Tegally H, Wilkinson E, Giovanetti M, Iranzadeh A, Fonseca V, Giandhari J, et al. Detection of a SARS-CoV-2 variant of concern in South Africa. Nature. 2021;592:438-43.

4. Tegally $\mathrm{H}$, Wilkinson $\mathrm{E}$, Giovanetti $\mathrm{M}$, Iranzadeh A, Fonseca V, Giandhari J, et al. Emergence and rapid spread of a new severe acute respiratory syndrome-related coronavirus 2 (SARS-CoV-2) lineage with multiple spike mutations in South Africa. medRxiv. Cold Spring Harbor Laboratory Press. 2020;2020.12.21.20248640.

5. Roquebert B, Trombert-Paolantoni S, Haim-Boukobza S, Lecorche E, Verdurme L, Foulongne V, et al. The SARS-CoV-2 B.1.351 lineage $(V O C \beta)$ is outgrowing the B.1.1.7 lineage (VOC a) in some French regions in April 2021. Euro Surveill. 2021;26.

6. Jassat W, Mudara C, Ozougwu L, Tempia S, Blumberg L, Davies M-A, et al. Difference in mortality among individuals admitted to hospital with COVID-19 during the first and second waves in South Africa : a cohort study. Lancet Glob Health. 2021 ;Sep;9(9):e1216-e1225

7. Abu-Raddad LJ, Chemaitelly H, Ayoub HH, Yassine HM, Benslimane FM, Khatib HAA, et al. Severity, criticality, and fatality of the SARS-CoV-2 Beta variant. Clin Infect Dis. 2021;ciab909

8. Funk T, Pharris A, Spiteri G, Bundle N, Melidou A, Carr M, et al. Characteristics of SARS-CoV-2 variants of concern B.1.1.7, B.1.351 or P.1: data from seven EU/EEA countries, weeks 38/2020 to 10/2021. Eurosurveillance. European Centre for Disease Prevention and Control.2021;26:2100348.

9. https://www.santepubliquefrance.fr/content/download/338799/file/analyse_risque_variants_20210421.pdf. Accessed 27 Nov 2021.

10. Subiros M. 2020. Covid-19 in Mayotte, epidemiological profile of one year of crisis. [Manuscript submitted for publication]

11. Churpek MM, Gupta S, Spicer AB, Parker WF, Fahrenbach J, Brenner SK, et al. Hospital-Level Variation in Death for Critically III Patients with COVID-19. Am J Respir Crit Care Med. American Thoracic Society - AJRCCM. 2021;204(4): 403-411 
12. von Elm E, Altman DG, Egger M, Pocock SJ, Gøtzsche PC, Vandenbroucke JP; STROBE Initiative. The Strengthening the Reporting of Observational Studies in Epidemiology (STROBE)statement: guidelines for reporting observational studies. J Clin Epidemiol. 2008;61(4):344-9.

13. Church S, Rogers E, Rockwood K, Theou O. A scoping review of the Clinical Frailty Scale. BMC Geriatrics. 2020;20:393.

14. Suliman LA, Abdelgawad TT, Farrag NS, Abdelwahab HW. Validity of ROX index in prediction of risk of intubation in patients with COVID-19 pneumonia. Adv Respir Med. 2021;89:1-7.

15. Ruch Y, Kaeuffer C, Ohana M, Labani A, Fabacher T, Bilbault P, et al. CT lung lesions as predictors of early death or ICU admission in COVID-19 patients. Clinical Microbiology and Infection. 2020;26:1417.e5-1417.e8.

16. Mahdjoub E, Mohammad W, Lefevre T, Debray M-P, Khalil A, Study Group§. Admission chest CT score predicts 5-day outcome in patients with COVID-19. Intensive Care Med. 2020;46:1648-50.

17. Marshall JC, Murthy S, Diaz J, Adhikari NK, Angus DC, Arabi YM, et al. A minimal common outcome measure set for COVID19 clinical research. The Lancet Infectious Diseases. 2020;20:e192-7.

18. Contentin L, Ehrmann S, Giraudeau B. Heterogeneity in the Definition of Mechanical Ventilation Duration and Ventilator-Free Days. Am J Respir Crit Care Med. 2014;189:998-1002.

19. Kulkarni VY, Sinha PK, Petare MC. Weighted Hybrid Decision Tree Model for Random Forest Classifier. J Inst Eng India Ser B. 2016; 97:209-17.

20. Hoogenboom WS, Pham A, Anand H, Fleysher R, Buczek A, Soby S, et al. Clinical characteristics of the first and second COVID-19 waves in the Bronx, New York: A retrospective cohort study. Lancet Regional Health Americas. Lancet Reg Health Am. 2021;133(23-24):1237-1247

21. Mayerhöfer T, Klein SJ, Peer A, Perschinka F, Lehner GF, Hasslacher J, et al. Changes in characteristics and outcomes of critically ill COVID-19 patients in Tyrol (Austria) over 1 year. Wien Klin Wochenschr. 2021; 133(23-24):1237-1247

22. Lambermont B, Rousseau Af, Seidel L, Thys M, Cavalleri J, Delanaye $P$ et al. Outcome Improvement Between the First Two Waves of the Coronavirus Disease 2019 Pandemic in a Single Tertiary-Care Hospital in Belgium. Critical care explorations. Crit Care Explor; 2021;3

23. Contou D, Fraissé M, Pajot O, Tirolien J-A, Mentec H, Plantefève G. Comparison between first and second wave among critically ill COVID-19 patients admitted to a French ICU: no prognostic improvement during the second wave? Crit Care. 2021;25:3.

24. Routsi C, Kokkoris S, Siempos I, Magira E, Kotanidou A, Zakynthinos S. Fewer Intubations but Higher Mortality Among Intubated Coronavirus Disease 2019 Patients During the Second Than the First Wave. Crit Care Explor. 2021;3:e531.

25. Chen H, Xie J, Su N, Wang J, Sun Q, Li S, et al. Corticosteroid Therapy Is Associated With Improved Outcome in Critically III Patients With COVID-19 With Hyperinflammatory Phenotype. Chest. 2021;159:1793-802.

26. Jassat W, Mudara C, Ozougwu L, Tempia S, Blumberg L, Davies M-A, et al. Increased mortality among individuals hospitalised with COVID-19 during the second wave in South Africa. medRxiv. Cold Spring Harbor Laboratory Press. 2021;2021.03.09.21253184.

27. Madahar P, Wunsch H, Jha P, Slutsky AS, Brodie D. Trends in COVID-19-related in-hospital mortality: lessons learned from nationwide samples. The Lancet Respiratory Medicine. Elsevier. 2021;9:322-4.

28. Damme WV, Dahake R, Delamou A, Ingelbeen B, Wouters E, Vanham G, et al. The COVID-19 pandemic: diverse contexts; different epidemics-how and why? BMJ Global Health. BMJ Specialist Journals. 2020;5:e003098.

29. Carbonell R, Urgelés S, Rodríguez A, Bodí M, Martín-Loeches I, Solé-Violán J, et al. Mortality comparison between the first and second/third waves among 3,795 critical COVID-19 patients with pneumonia admitted to the ICU: A multicentre retrospective cohort study. The Lancet Regional Health - Europe. 2021;11:100243.

30. Bravata DM, Perkins AJ, Myers LJ, Arling G, Zhang Y, Zillich AJ, et al. Association of Intensive Care Unit Patient Load and Demand with Mortality Rates in US Department of Veterans Affairs Hospitals During the COVID-19 Pandemic. JAMA Netw Open. 2021;4:e2034266.

31. Rossman H, Meir T, Somer J, Shilo S, Gutman R, Ben Arie A et al. Hospital load and increased COVID-19 related mortality in Israel. Nature communications. Nat Commun. 2021; 12: 1904. 
32. Ritter LA, Britton N, Heil EL, Teeter WA, Murthi SB, Chow JH, et al. The Impact of Corticosteroids on Secondary Infection and Mortality in Critically III COVID-19 Patients. J Intensive Care Med. 2021;8850666211032175.

33. Giamarellos-Bourboulis EJ, Netea MG, Rovina N, Akinosoglou K, Antoniadou A, Antonakos N, et al. Complex Immune Dysregulation in COVID-19 Patients with Severe Respiratory Failure. Cell Host Microbe. 2020;27:992-1000.e3.

34. Ratcliff J, Nguyen D, Fish M, Rynne J, Jennings A, Williams S, et al. Virological and serological characterization of critically ill patients with COVID-19 in the UK: Interactions of viral load, antibody status and B.1.1.7 variant infection. J Infect Dis. 2021;jiab283.

35. on behalf of the coVAPid study Group, Rouzé A, Martin-Loeches I, Povoa P, Makris D, Artigas A, et al. Relationship between SARS-CoV-2 infection and the incidence of ventilator-associated lower respiratory tract infections: a European multicenter cohort study. Intensive Care Med. 2021;47:188-98.

36. Argenziano MG, Bruce SL, Slater CL, Tiao JR, Baldwin MR, Barr RG, et al. Characterization and clinical course of 1000 patients with coronavirus disease 2019 in New York: retrospective case series. BMJ. British Medical Journal Publishing Group. 2020;369:m1996.

37. COVID-ICU Group on behalf of the REVA Network and the COVID-ICU Investigators. Clinical characteristics and day-90 outcomes of 4244 critically ill adults with COVID-19: a prospective cohort study. Intensive Care Med. 2021;47:60-73.

38. Florence S, Lebas J, Parizot I, Sissoko D, Querre M, Paquet C, et al. [Migration, health and access to care in Mayotte Island in 2007: lessons learned from a representative survey]. Rev Epidemiol Sante Publique. 2010;58:237-44.

39. Fan G, Yang Z, Lin Q, Zhao S, Yang L, He D. Decreased Case Fatality Rate of COVID-19 in the Second Wave: A study in 53 countries or regions. Transbound Emerg Dis. 2021;68:213-5.

\section{Figures}

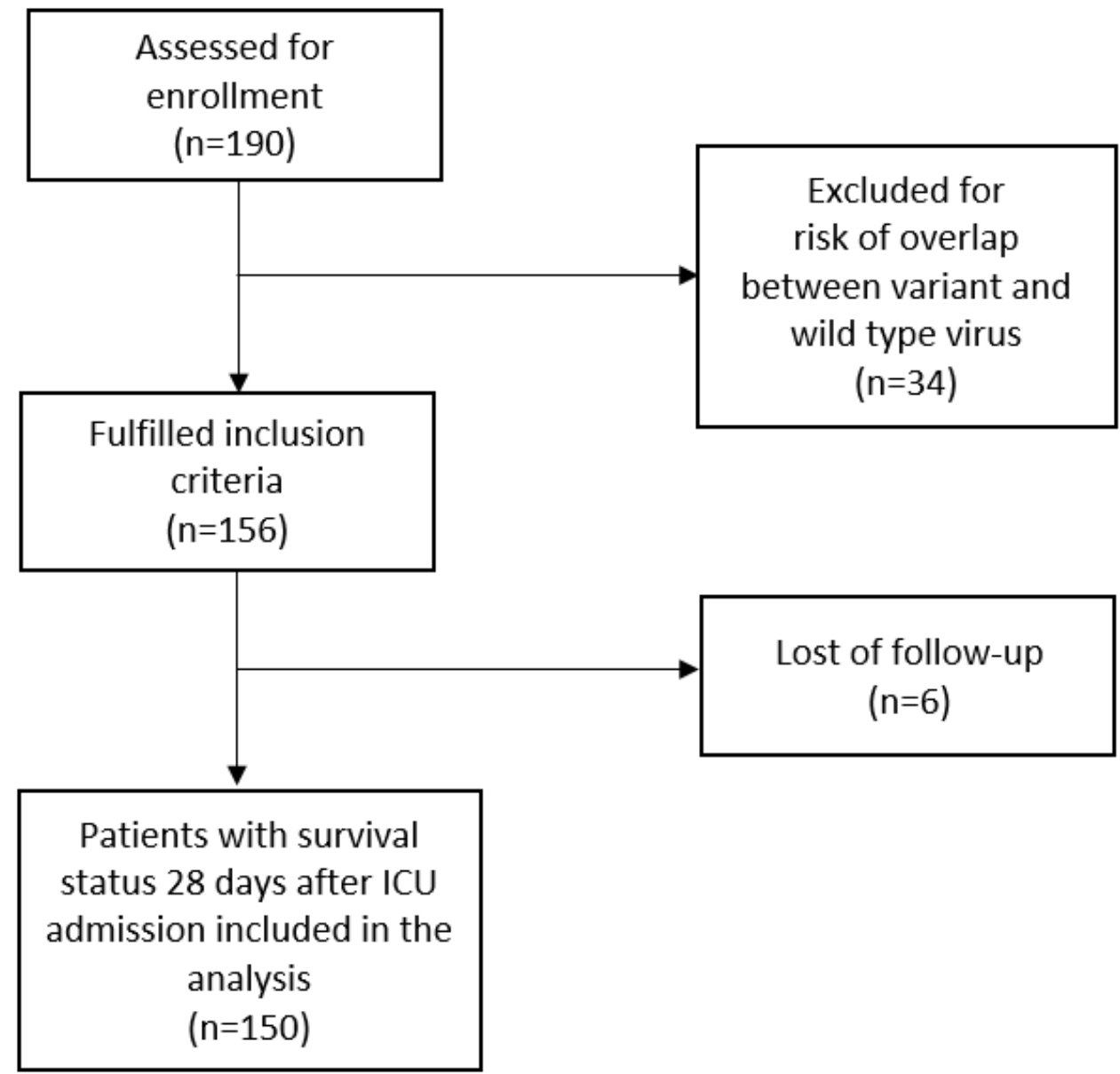

Figure 1 
Flowchart

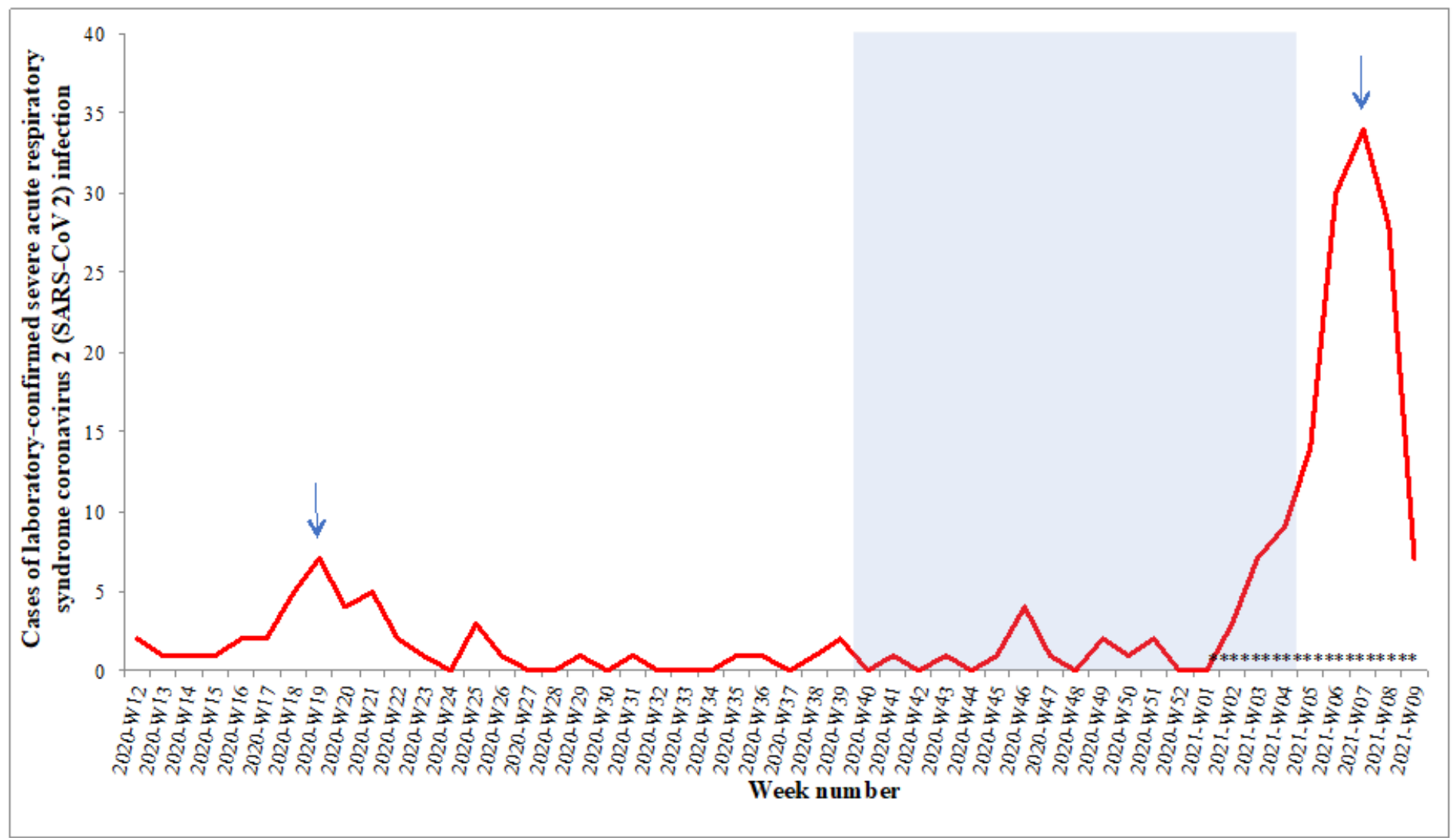

Definition of waves according to ICU admission data.

Blue area shows the weeks 40 to 4 excluded to avoid risk of overlap between wild-type and variant virus.

Blue arrows show the peak of the two waves.

*viral whole genome sequencing was performed for 23 critically ill patients: the majority $(\mathrm{N}=20)$ had the $20 \mathrm{H} / 501 \mathrm{Y}$.V2 variant.

\section{Figure 2}

Epidemic curve of laboratory confirmed severe acute respiratory syndrome coronavirus 2 during wave 1 and 2. 


\section{Mean Decrease Accuracy}

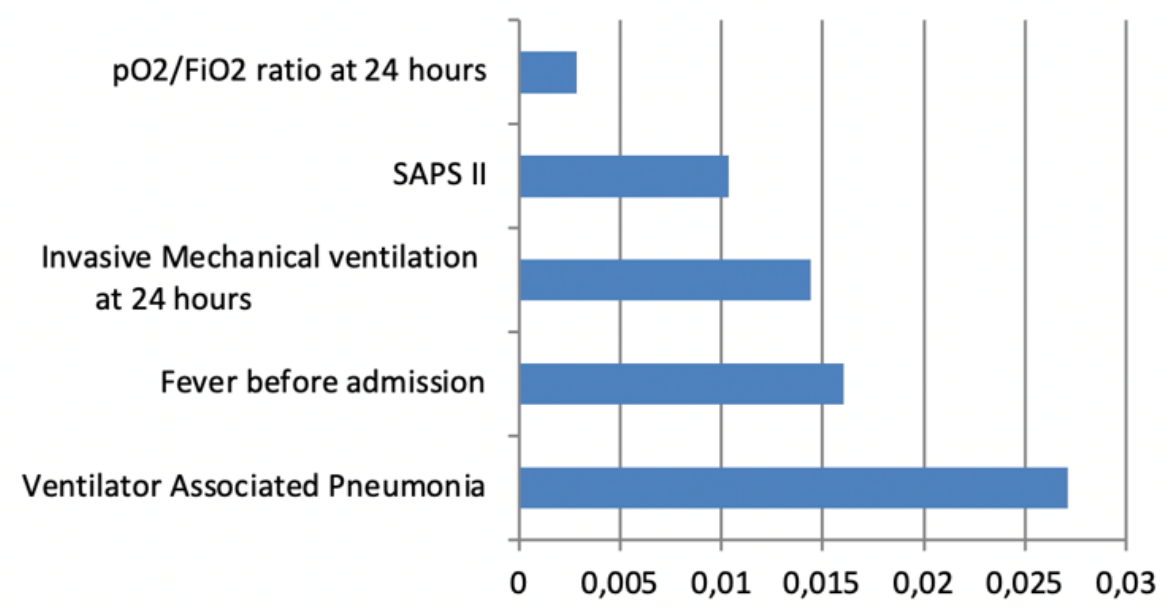

\section{Mean Decrease Gini}

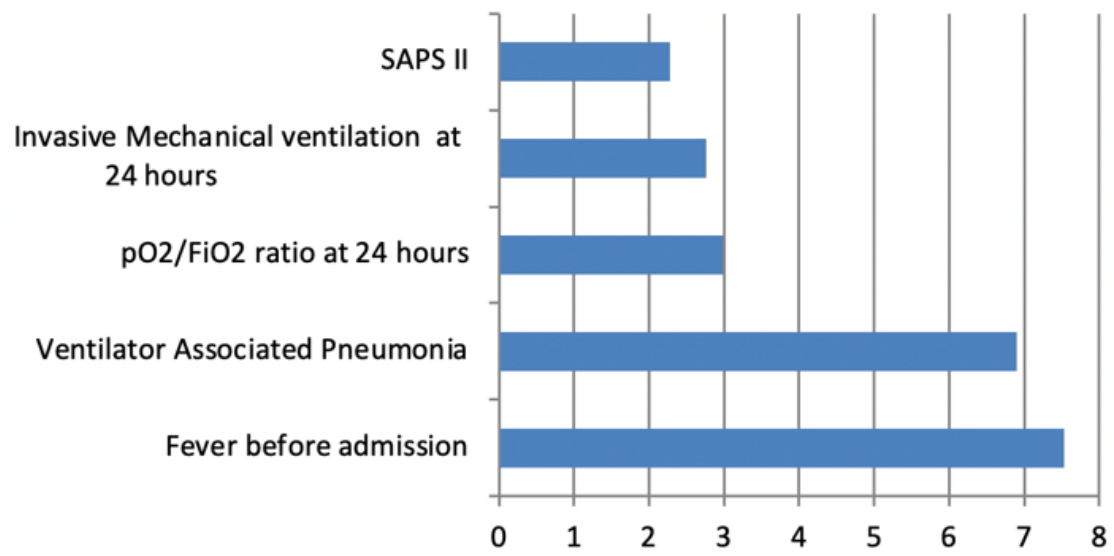

SAPS: Simplified Acute Physiology score

Figure 3

Variable importance plot to predict waves based on Random Forest model. 